\title{
Mimicking reproductive endocrinology to achieve successful pregnancy in frozen embryo replacement cycle in luteinized unruptured follicle (LUF)
}

\author{
Namita Jain ${ }^{1 *}$, Sonia Malik², Ved Prakash ${ }^{3}$
}

\begin{abstract}
${ }^{1}$ Department of Obstetrics and Gynecology, MGMC, Jaipur, Rajasthan, India
${ }^{2}$ Department of Obstetrics and Gynecology, Southend Fertility and IVF, Delhi, India

${ }^{3}$ Department of Embryology, Southend Fertility and IVF, Delhi, India
\end{abstract}

Received: 18 September 2018

Accepted: 22 October 2018

\author{
*Correspondence: \\ Dr. Namita Jain, \\ E-mail: namita.hardonian@gmail.com
}

Copyright: (c) the author(s), publisher and licensee Medip Academy. This is an open-access article distributed under the terms of the Creative Commons Attribution Non-Commercial License, which permits unrestricted non-commercial use, distribution, and reproduction in any medium, provided the original work is properly cited.

\begin{abstract}
Frozen embryo replacement cycles are commonly performed in all ART centres for various indications. In FER cycles, aim is to achieve the synchronization between the endometrium and the embryo. It can be undertaken in a natural or in an artificially prepared endometrium. Artificial preparation utilizes either the ovulation induction agents or hormones. Luteinized unruptured follicle is commonly encountered nowadays due to better resonance USG machines and frequent monitoring. It is still unclear among the practitioners whether to perform an embryo transfer in LUF. In this case report, authors are highlighting that in case of FER cycles using ovulation induction agent, despite inability to ovulate (LUF), if authors are able to achieve optimum synchronization between endometrium and the embryo using USG and serum hormonal levels, successful outcome could be expected.
\end{abstract}

Keywords: Embryo, Endometrium, Frozen

\section{INTRODUCTION}

More we move toward the advancement in assisted reproductive technology, better becomes our understanding of the reproductive endocrinology and vice versa. Understanding reproductive endocrinology is the basic requirement for achieving success in ART. In FET cycles, aim is to naturally or artificially create an environment which is able to sustain a pregnancy and it's possible only if one knows how to mimic and what to expect in terms of blood hormone levels., ${ }^{1,2}$ Different regimens are utilized for endometrial preparation like natural cycle, hormone replacement or stimulated cycle. Currently there is insufficient evidence to support the use of one cycle regimen in preference to another in preparation for FET in sub-fertile women with regular ovulatory cycles. ${ }^{3}$ Luteinized unruptured follicle (LUF) is considered as one of the causes of subfertility. LUF is observed in $10 \%$ of natural menstrual cycles in fertile women, but in stimulated cycles it is higher. ${ }^{4}$ The incidence of LUF has been reported to be $25-43 \%$ in infertile women ${ }^{5}$. Concerns do exist regarding impact on success of the embryo transfer in a stimulated cycle with LUF. No definite guideline exists whether to go ahead with embryo transfer or cycle cancellation.

\section{CASE REPORT}

A 42-year-old female presented with secondary infertility for 5 years. She conceived spontaneously 5 years back and delivered a baby girl at full term by caesarean. Following which she had three missed abortions, out of which she conceived naturally twice and the last one was an IVF conceived pregnancy (at UK). She was 
investigated for recurrent abortions and diagnosed with undifferentiated connective tissue disorder (Ro-52, Ro62, anti-nuclear antibody-positive), for which she was started on Tab Hydroxychloroquine 200mg twice daily. Her menstrual cycles were regular with 28 days cycle. She is known case of hypothyroidism controlled on tab thyroxine $25 \mathrm{mcg}$ and had history of bluish discoloration of peripheral extremities and pigmentation over legs, diagnosed as lupus on skin biopsy. Mother had left mastectomy in view of breast cancer at age of 61 years and brother died of severe deep vein thrombosis (Protein $\mathrm{C}$ deficiency) at age of 30 years. Authors planned FET with donor eggs for her in view of her age and two failed IVF cycles. She came to India for a limited time just before her periods were due. First hurdle authors encountered was her failure to get a period. In view of limited time frame, authors did a gentle endometrial curettage and gave her 4 days of antagonist. Authors started with Letroz, stimulated FET for her in order to decrease estrogen exposure. She developed one follicle on right side $20 \mathrm{~mm}$ size and her serum estradiol level was $255 \mathrm{pg} / \mathrm{ml}$ on day of trigger, and authors started her on injection lonopin and ecosprin in view of her medical history and poor vascularity in the endometrium. But unfortunately, follicle did not rupture even on day 3 of the trigger. Despite this, authors went ahead with the transfer after five days of progesterone switchover, as authors were satisfied with the character of the endometrium and her hormonal profile on day of trigger and two days after trigger. Authors did a day 5 transfer (2 Blastocyst) for her and continued with inj lonopin and gave her good luteal phase support (Hcg and Progesterone). Her bHcg came out to be 5149 after 16 days of transfer and USG showed twin gestational sac, out of which one sac showed fetal heart later on and the other sac disappeared. Her pregnancy went uneventful and she delivered a healthy baby at 38 weeks by caesarean section.

\section{DISCUSSION}

Frozen embryo replacement is a proven method of achieving successful pregnancy which allows better synchronization between the endometrium and the embryo. ${ }^{1}$ Factors which affect successful implantation are embryo quality, synchronization between embryo and endometrium, and endometrial receptivity. ${ }^{2}$ Various regimens exists for endometrial preparation. ${ }^{6}$ In this case, authors chose letrozole- an aromatase inhibitor stimulated cycle in order to reduce the concern related to increased estrogen levels with hormone replacement FER cycle in view of undifferentiated connective tissue disorder and family history of breast cancer and DVT.

Also, letrozole favors single-follicle development with no negative effects on endometrium and cervical mucus. ${ }^{7}$ Letrozole enable full endometrial pinopode expression and improves endometrial receptivity by increasing integrin aVb3 expression on the endometrium during implantation. ${ }^{8}$ It may be an effective drug preparing the endometrium for FET, but few studies have investigated its clinical efficacy.

Luteinized unruptured follicle (LUF) syndrome is a recognized cause of ovulation failure. It occurs in $10 \%$ of the menstrual cycle in a fertile woman but incidence increases with stimulated cycles. ${ }^{4}$ Also, it is on the rise due to availability of better imaging modalities. Recent studies have shown that the endometrium proliferates more slowly in LUF cycles than in ovulatory cycles, and women with LUF cycles have a shortened luteal phase, reduced $\mathrm{P}$ level and inadequate luteal function. ${ }^{9}$ Many centres do not perform FET in women with LUFS due to the controversial status of impact of LUF on FET cycles. In the abovementioned case, embryo transfer was performed despite LUFS on the basis of the character of the endometrium and correlated it with the blood hormone levels of an ovulatory cycle after informing the couple and successfully achieved the pregnancy.

In a study by $\mathrm{Xu} \mathrm{W}$ et al, the impact of LUF on endometrial receptivity was examined. ${ }^{10}$ They found significantly lower mean expression intensities of integrin $\alpha v \beta 3$ in endometrium of LUF patients $(114.90 \pm 11.38)$ than those in control group $(191.34 \pm 1.82)(\mathrm{P}<0.01)$. This change in integrin $\alpha v \beta 3$ expression was in positive relation with serum $\mathrm{P}$ level $(\mathrm{r}=0.77, \mathrm{P}<0.01)$, but no significant relationship with serum E2 level $(r=0.01$, $\mathrm{P}>0.05)$. They concluded that the low expressions of integrin $\alpha v \beta 3$ also suggested that the delayed implantation and the impaired endometrial receptivity had impact on embryonic implantation.

However, in a study by Wang $\mathrm{L}$ et al, the clinical outcome of FET cycle in the two groups (LUF and ovulation group) was not different as shown in Table $1 .{ }^{4}$

Table 1: The outcome of FET in two groups.

\begin{tabular}{|llll|} 
Group & $\begin{array}{l}\text { Clinical } \\
\text { pregnancy } \\
\text { rate }\end{array}$ & $\begin{array}{l}\text { Ongoing } \\
\text { pregnancy } \\
\text { rate }\end{array}$ & $\begin{array}{l}\text { Live } \\
\text { birth } \\
\text { rate }\end{array}$ \\
\hline LUF & $12.76 \%$ & $27.78 \%$ & $19.44 \%$ \\
\hline Ovulation & $14.74 \%$ & $31.29 \%$ & $28.29 \%$ \\
\hline p-value & $>0.05$ & $>0.05$ & $>0.05$ \\
\hline
\end{tabular}

They concluded that LUF does not affect the clinical outcomes of FET. No prospective studies exist till date on the impact of LUF cycles on the clinical outcomes of FET cycles. There should be clear cut criteria's which needs to be fulfilled in LUF cycles considering FET based on ultrasound parameters and its correlation with the blood hormone levels.

\section{CONCLUSION}

FET could be performed in LUF cases once desired endometrial character and endometrial thickness with the blood hormone levels equivalent to an ovulatory cycle are achieved. This needs to be supplemented with the 
adequate luteal phase support to rectify the possible inadequate luteal phase function and facilitate the embryo implantation and development. This had not been supported by experiments of larger sample size. Prospective study analysing the impact of LUF on FET cycles needs to be conducted.

Funding: No funding sources Conflict of interest: None declared

Ethical approval: Not required

\section{REFERENCES}

1. Aflatoonian A, Oskouian H, Ahmadi S, Oskouian L. Can fresh embryo transfers be replaced by cryopreserved-thawed embryo transfers in assisted reproductive cycles? A randomized controlled trial. J Assist Reprod Genet. 2010;27:357-63.

2. Guzeloglu-Kayisli O, Basar M, Arici A. Basic aspects of implantation. Reprod Biomed Online. 2007;15:728-39.

3. Ghobara T, Gelbaya TA, Ayeleke R. Cycle regimens for frozen-thawed embryo transfer. Cochrane Database of Systematic Reviews. 2017;(7):CD003414.

4. Wang L, Qiao J, Liu P, Lian Y. Effect of luteinized unruptured follicle cycles on clinical outcomes of frozen thawed embryo transfer in Chinese women. J Assisted Reprod Genet. 2008;25(6):229-33.

5. Azmoodeh A, Manesh MP, Asbagh FA, Ghaseminejad A, Hamzehgardeshi Z. Effects of
letrozole-HMG and clomiphene-HMG on incidence of luteinized unruptured follicle syndrome in infertile women undergoing induction ovulation and intrauterine insemination: a randomised trial. Global J Health Sci. 2016;8(4):244.

6. Wright KP, Guibert J, Weitzen S, Davy C, Fauque P, Olivennes F. Artificial versus stimulated cycles for endometrial preparation prior to frozen-thawed embryo transfer. Reprod Biomed Online. 2006;13:321-5.

7. Badawy A, Abdel Aal I, Abulatta M. Clomiphene citrate or letrozole for ovulation induction in women with polycystic ovarian syndrome: a prospective randomized trial. Fertil Steril. 2009;92:849-52.

8. Bao SH, Sheng SL, Peng YF, Lin QD. Effects of letrozole and clomiphene citrate on the expression of HOXA10 and integrin avb3 in uterine epithelium of rats. Fertil Steril. 2009;91:244-8.

9. Murdoch WJ, Gottsch ML. Proteolytic mechanisms in the ovulatory folliculo-luteal transformation. Connect Tissue Res, 2003;44(1):50-7.

10. Xu W, Yang J, Jiang L, Hu J. Impact of luteinized unruptured follicles on endometrial receptivity. J Huazhong Univ Sci Technolog Med Sci. 2011;31:181-4.

Cite this article as: Jain N, Malik S, Prakash V. Mimicking reproductive endocrinology to achieve successful pregnancy in frozen embryo replacement cycle in luteinized unruptured follicle (LUF). Int $\mathbf{J}$ Reprod Contracept Obstet Gynecol 2018;7:5187-9. 